\title{
German Heart Centre Munich -45 years of surgery in adults with congenital heart defects: from primary corrections of septal defects and coarctation to complex reoperations
}

\author{
Jelena Pabst von Ohain ${ }^{1,2}$, Eleonora Tonino ${ }^{1,2}$, Harald Kaemmerer ${ }^{3}$, Julie Cleuziou ${ }^{1,2}$, Peter Ewert ${ }^{3}$, \\ Rüdiger Lange ${ }^{4}$, Jürgen Hörer ${ }^{1,2}$
}

${ }^{1}$ Department of Congenital and Paediatric Heart Surgery, German Heart Centre Munich, Technische Universität München, Munich, Germany; ${ }^{2}$ Division of Congenital and Paediatric Heart Surgery, University Hospital of Munich, Ludwig-Maximilian-Universität, Munich, Germany; ${ }^{3}$ Department of Congenital Heart Disease and Paediatric Cardiology, German Heart Centre Munich, Technische Universität München, Munich, Germany; ${ }^{4}$ Department of Cardiovascular Surgery, German Heart Centre Munich, Technische Universität München, Munich, Germany Contributions: (I) Conception and design: J Hörer, J Pabst von Ohain; (II) Administrative support: J Hörer; (III) Provision of study materials or patients: J Hörer, R Lange, H Kaemmerer, P Ewert; (IV) Collection and assembly of data: E Tonino, J Pabst von Ohain; (V) Data analysis and interpretation: J Pabst von Ohain; (VI) Manuscript writing: All authors; (VII) Final approval of manuscript: All authors.

Correspondence to: Jelena Pabst von Ohain, MD, PhD. Division of Congenital and Paediatric Heart Surgery, University Hospital of Munich, Marchioninistraße 15, D-81377 Munich, Germany. Email: j.pabst.von.ohain@med.uni-muenchen.de; j.pabst.von.ohain@dhm.mhn.de.

Background: Our historical overview in the form of a cohort study aimed to describe the changes in the cardiac operations in adults with congenital heart disease (ACHD), over 45 years in the German Heart Centre in Munich.

Methods: The study population comprised all consecutive patients aged 18 or more, who underwent surgery for congenital heart disease (CHD) at the German Heart Centre Munich, between 1974 and 2018. Operations were coded according to the Adult Congenital Heart Surgery (ACHS) score. Two-tailed chisquare test was used for testing on differences in the frequency of procedural groups between the decades.

Results: During the examined 45-year period, 2,882 operations were performed on ACHD. The number of operations per year increased with a correlation coefficient $r=0.533, \mathrm{P}<0.001$. Overall operative mortality was $3.2 \%$. There was no significant difference in mortality over the decades. The percentage of primary CHD diagnosis being the indication for the operation was $99 \%$ in the 1970 s and decreased significantly to $56 \%$ in the $2010 \mathrm{~s}, \mathrm{P}<0.001$. There was a significant decrease in the relative frequency of atrial septal defect closures from $45 \%$ in the 1970 s and 1980 s to $9 \%$ in 2010 s $(\mathrm{P}<0.001)$. Coarctation repair made up $15 \%$ of all operations in the $1970 \mathrm{~s}$, then dropped significantly to $1 \%$ in the $2010 \mathrm{~s}(\mathrm{P}<0.001)$. The percentage of reoperations increased significantly from $7 \%$ in the 1970 s to $50 \%$ in $2010 \mathrm{~s}(\mathrm{P}<0.001)$.

Conclusions: The spectrum of cardiac surgery in ACHD changed significantly over the last 45 years, from primary repair of septal defects and coarctation of the aorta in the 1970s to complex reoperations in the 2010 s.

Keywords: Grown-up congenital heart disease; congenital heart surgery; historical review; adults with congenital heart disease

Submitted Sep 28, 2020. Accepted for publication Jan 08, 2021.

doi: $10.21037 / \mathrm{cdt}-20-831$

View this article at: http://dx.doi.org/10.21037/cdt-20-831

\footnotetext{
$\wedge$ ORCID: 0000-0001-7947-8637.
} 


\section{Introduction}

Advances in paediatric cardiology and paediatric cardiac surgery have significantly increased the survival of patients with congenital heart disease (CHD) $(1,2)$. Current studies show that nowadays, more than $90 \%$ of CHD patients reach adulthood $(3,4)$. Since almost four decades, there is a noticeable increase in the prevalence of adults with congenital heart disease (ACHD), who now make up two-thirds of all patients with CHD (5). With the increasing age of ACHD, a greater cumulative percentage will require a cardiac operation or reoperation. The range of cardiac surgery performed in ACHD covers a broad field from first corrective surgery, over reoperations to treat residual defects and long-term consequences of CHD or previous treatments, to surgery for acquired heart disease (6-8). The spectrum of cardiac operations in ACHD changed over time and shifted away from the primary repair, which is nowadays almost always achieved already in paediatric age $(6,7)$. Operative mortality for cardiac surgery in ACHD ranges from $1.8 \%$ to $3.6 \%(6,7,9,10)$.

Our historical overview in the form of a cohort study aimed to describe the changes in the performed cardiac operations in ACHD, over 45 years in the German Heart Centre in Munich. We present the following article in accordance with the STROBE reporting checklist (available at http://dx.doi.org/10.21037/cdt-20-831).

\section{Methods}

\section{Study population}

The study population comprised all consecutive patients aged 18 or more, who underwent surgery for CHD at the German Heart Centre Munich, between 1974 and 2018. Institutional Review Board approval was obtained to conduct this study (Ethikkommission an der Technischen Universität München 40/20 S). The study was conducted in accordance with the Declaration of Helsinki (as revised in 2013) (11).

Age of a patient, primary diagnosis and the diagnosis leading to the index operation, the performed operation, and the status at the hospital discharge or the $30^{\text {th }}$ postoperative day were obtained from the hospital records. There was no missing data.

\section{Operations}

Operations were coded according to the Adult Congenital
Heart Surgery (ACHS) score (12). For operations consisting of multiple concomitant procedures, the procedure with the highest ACHS score was set as the primary procedure. Operations on bicuspid aortic valves (AV) were included only in patients who had had a prior intervention or operation on the AV during childhood or adolescence. Pacemaker procedures were included only if a thoracotomy/ sternotomy was performed for lead positioning. Unplanned reoperations during the same hospital admission as the primary surgery were excluded and coded as complications. Reoperations were coded in 1 of the 3 following groups: $1^{\text {st }}$, $2^{\text {nd }}$ or $3^{\text {rd }}$ redo-sternotomy; $4^{\text {th }}+$ redo-sternotomy or a redothoracotomy.

\section{Outcome}

Operative mortality was defined as the death of any cause, occurring within 30 days after surgery in or out of the hospital, or after 30 days during the same hospitalisation subsequent to the operation (13).

\section{Statistics}

All of the results were separated into 5 decades: 1974-1979 ('70s); 1980-1989 ('80s); 1990-1999 ('90s); 2000-2009 ('00s) and 2010-2018 ('10s).

Frequencies are given as absolute numbers and percentages. Continuous variables are expressed as mean and standard deviation if normally distributed or median and interquartile range (IQR; $1^{\text {st }}-3^{\text {rd }}$ quartile) for non-normal distribution.

Changes in the number of operations per year were analysed with linear regression and one-way ANOVA test. Median age between decades was compared using the nonparametric median test for independent samples.

Differences between the decades in mortality, primary versus new diagnosis leading to the cardiac operation, as well as first operation versus reoperations, were calculated using the two-tailed chi-square test. The same test was used for testing on differences in the frequency of procedural groups between the decades, for each procedural group.

Analyses were performed with IBM SPSS Statistics for Windows, version 26.0.

\section{Results}

During the examined 45-year period, 2,882 operations, including 4,161 procedures, were performed on adults with CHD. The number of operations per year increased 
with a correlation coefficient $\mathrm{r}=0.533$ (95\% confidence interval: $0.353-1.029), \mathrm{P}<0.001$ (Figure 1). Overall operative mortality was $3.2 \%$. There was no statistically significant difference in mortality over the decades ( $\mathrm{P}$ ranging from 0.206 to 1.000 ) (Figure 1).

The age distribution is shown in Figure $2 A$. Figure $2 B$ shows the age groups of ACHD as a cumulative percentage per decade. The median age in the '70s, ' $80 \mathrm{~s}$, '90s, '00s and ' 10 s was 32.6 (23.2-42.3), 30.2 (22.0-44.4), 32.3 (23.8-47.1), 30.5 (22.6-41.1) and 34.1 (25.7-46.8). The median was statistically higher in the ' $10 \mathrm{~s}$ when compared to the " $80 \mathrm{~s}$

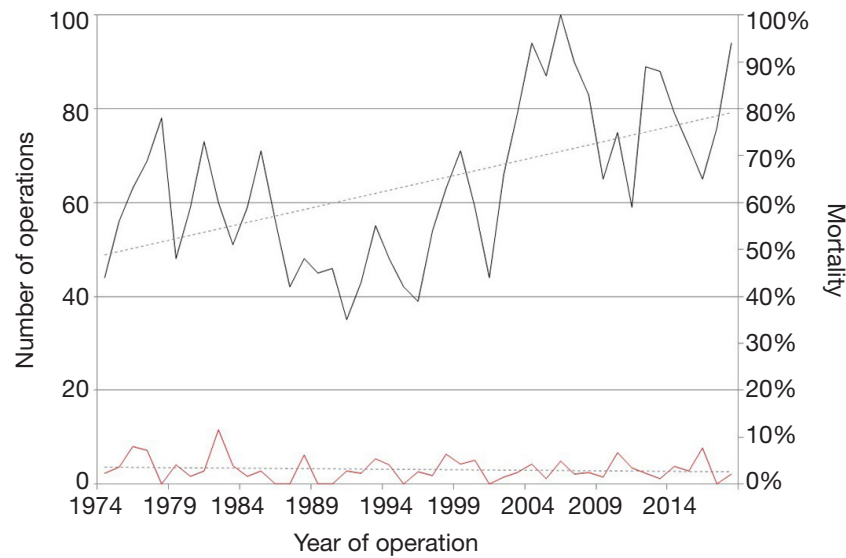

Figure 1 The number of operations and mortality per year performed on adults with congenital heart disease undergoing cardiac surgery between 1974 and 2018 in German Heart Centre Munich. The number of operations is depicted with a black line. Mortality is shown with a red line and a secondary axis. The grey interrupted lines are the trendlines. and ' $00(\mathrm{P}<0.001)$.

In 1,871 operations a single procedure was performed, in 743 operations two procedures, and in 268 operations three concomitant procedures were performed (Table 1). The three most frequently performed procedures were the closure of the atrial septal defect (ASD), closure of a ventricular septal defect (VSD) and AV replacement. These three procedures were part of $40.2 \%, 8.7 \%$, and $6.9 \%$ of the 2,882 operations, respectively.

Figure $3 A$ shows the percentage of primary versus new diagnosis leading to the index cardiac operation. The percentage of primary CHD diagnosis being the indication for the operation decreased statistically significantly each decade up to the '00s $(\mathrm{P}<0.001)$ and then stayed stable on ca. $55-60 \%(\mathrm{P}=0.152)$. Figure $3 B$ shows the percentage of reoperations in comparison to primary operations over the decades. The percentage of reoperations increased significantly each decade up to the '00s $(\mathrm{P}<0.001)$ and then stayed stable on $c a$. $50 \%$ of all performed operations $(\mathrm{P}=0.496)$. The $4^{\text {th }}+$ reoperations were on a stable level in the ' 90 s and ' 00 s $(\mathrm{P}=0.860)$, reaching $7.4 \%$ and $8.2 \%$ of all reoperations, respectively. In the ' 10 s, there was a significant rise in these operations to $15.5 \%$ of all reoperations $(\mathrm{P}=0.008)$.

The relative frequency of the first procedures over decades is shown in Figure 4.

Septal defects (Figure $4 A$ ): there was a significant decrease in the relative frequency of ASD closures in the '00s and ' 10 s compared to all earlier decades, $(\mathrm{P}<0.001)$. The relative frequency of partial anomalous pulmonary venous connection (PAPVC) correction first reduced
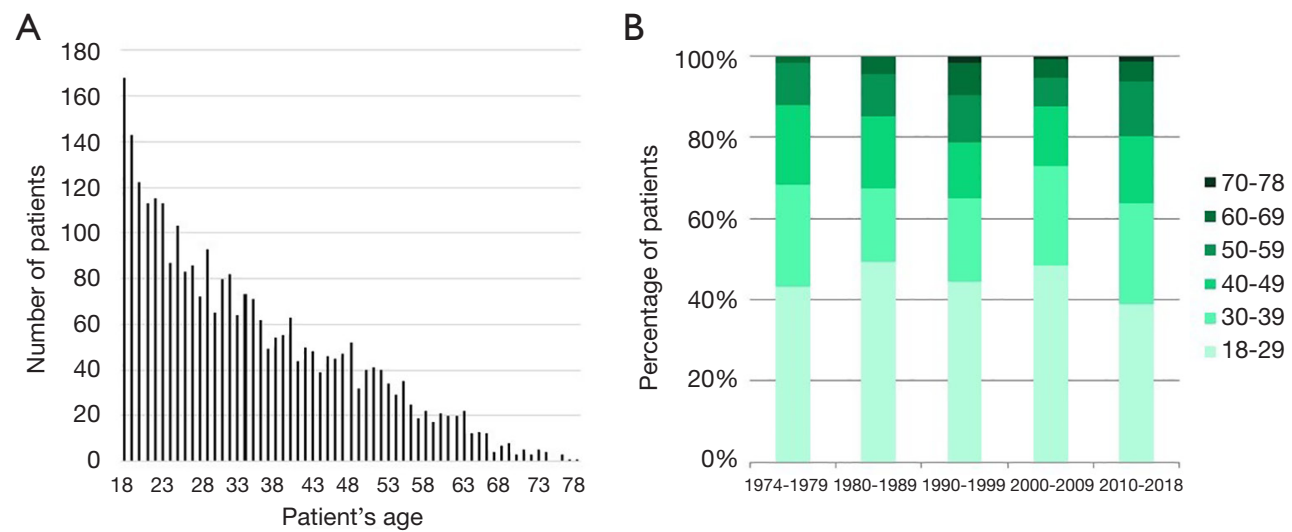

Figure 2 Adults with congenital heart disease undergoing cardiac surgery between 1974 and 2018 in German Heart Centre Munich. (A) Distribution of age; (B) age groups, shown as a cumulative percentage per decade. 
Table 1 Frequency of procedures performed as primary procedure and as additional procedures on adults with congenital heart disease undergoing cardiac surgery between 1974 and 2018 in German Heart Centre Munich

\begin{tabular}{|c|c|c|c|c|c|}
\hline Procedural group & $\begin{array}{l}\text { First procedure } \\
\qquad(n=2,882)\end{array}$ & $\begin{array}{l}\text { Second procedure } \\
\qquad(n=1,011)\end{array}$ & $\begin{array}{l}\text { Third procedure } \\
\qquad(\mathrm{n}=268)\end{array}$ & Total & $\begin{array}{c}\text { Percentage of } \\
2,882 \text { operations }\end{array}$ \\
\hline ASD & 860 & 244 & 53 & 1,157 & 40.15 \\
\hline VSD & 171 & 43 & 36 & 250 & 8.67 \\
\hline AV replacement & 151 & 35 & 13 & 199 & 6.90 \\
\hline MV repair & 73 & 62 & 1 & 136 & 4.72 \\
\hline PAPVC repair & 115 & 17 & 1 & 133 & 4.61 \\
\hline Conduit RV-PA & 109 & 17 & 5 & 131 & 4.55 \\
\hline Aortic stenosis, subvalvular & 33 & 50 & 11 & 94 & 3.26 \\
\hline RVOT repair & 42 & 44 & 7 & 93 & 3.23 \\
\hline Pulmonic valvuloplasty & 50 & 27 & 8 & 85 & 2.95 \\
\hline TV replacement & 73 & 6 & 2 & 81 & 2.81 \\
\hline TOF repair & 76 & 2 & 0 & 78 & 2.71 \\
\hline PA reconstruction & 33 & 29 & 1 & 63 & 2.19 \\
\hline PV replacement & 27 & 27 & 1 & 55 & 1.91 \\
\hline Aortic root replacement, non-valve-sparing & 45 & 1 & 0 & 46 & 1.60 \\
\hline Valve-sparing aortic root replacement & 33 & 11 & 0 & 44 & 1.53 \\
\hline Aortic aneurysm & 37 & 6 & 0 & 43 & 1.49 \\
\hline Fontan procedure & 33 & 0 & 0 & 33 & 1.15 \\
\hline Shunt, systemic to pulmonary & 30 & 0 & 0 & 30 & 1.04 \\
\hline Coronary artery bypass & 21 & 3 & 1 & 25 & 0.87 \\
\hline Fontan revision & 23 & 0 & 0 & 23 & 0.80 \\
\hline Systemic venous stenosis repair & 21 & 1 & 0 & 22 & 0.76 \\
\hline Aortic stenosis, supravalvular & 7 & 9 & 4 & 20 & 0.69 \\
\hline DCRV & 8 & 11 & 1 & 20 & 0.69 \\
\hline
\end{tabular}

Table 1 (continued) 
Table 1 (continued)

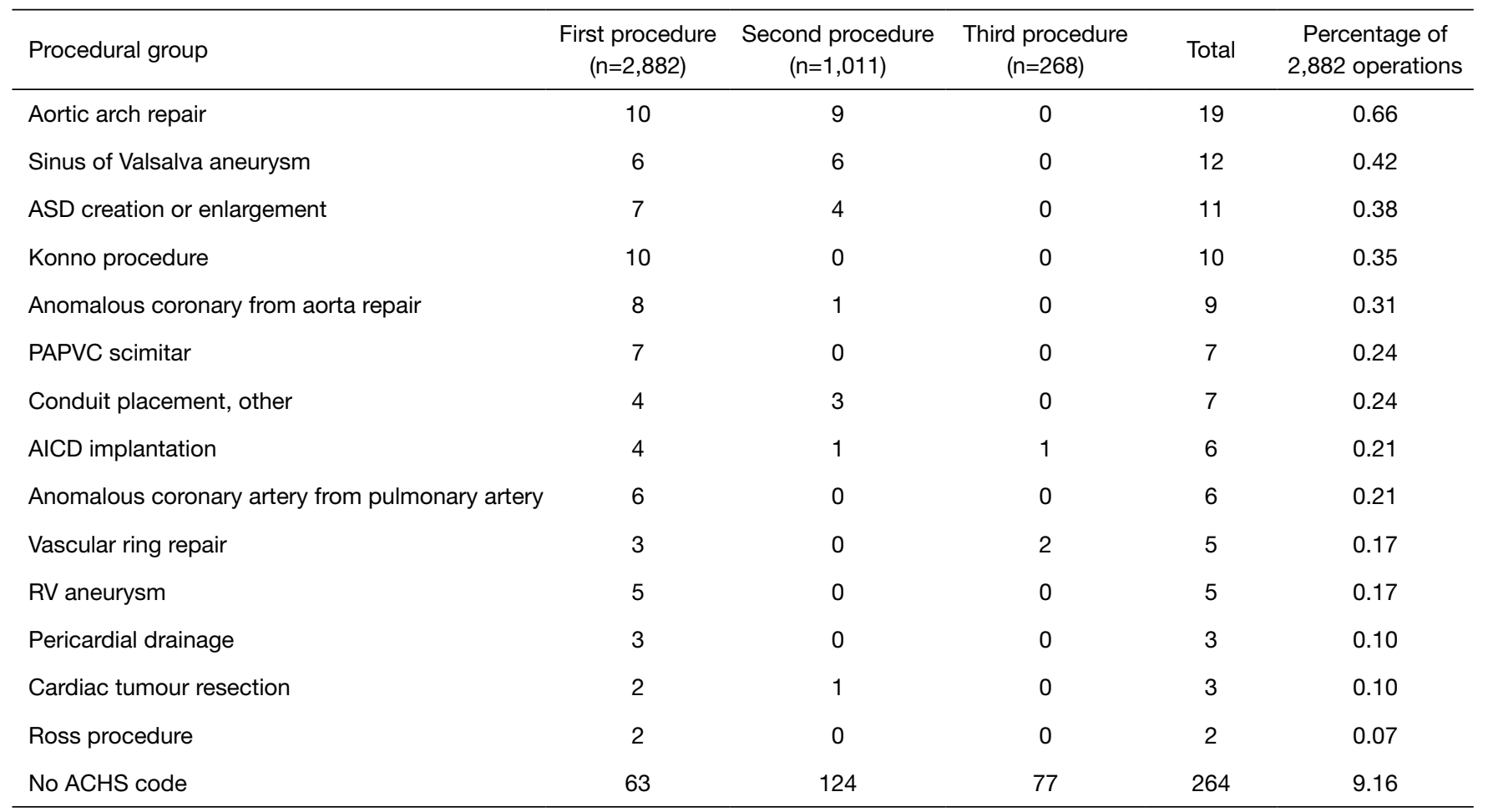

ACHS, adult congenital heart surgery; AICD, automatic implantable cardioverter defibrillator; ASD, atrial septal defect; AV, aortic valve; AV canal, atrioventricular canal; DCRV, double-chambered right ventricle; MV, mitral valve; PA, pulmonary artery; PAPVC, partial anomalous pulmonary venous connection; PV, pulmonary valve; RV, right ventricle; RV-PA, right ventricle to the pulmonary artery; RVOT, right ventricular outflow tract; TOF, tetralogy of Fallot; TV, tricuspid valve; VSD, ventricular septal defect.
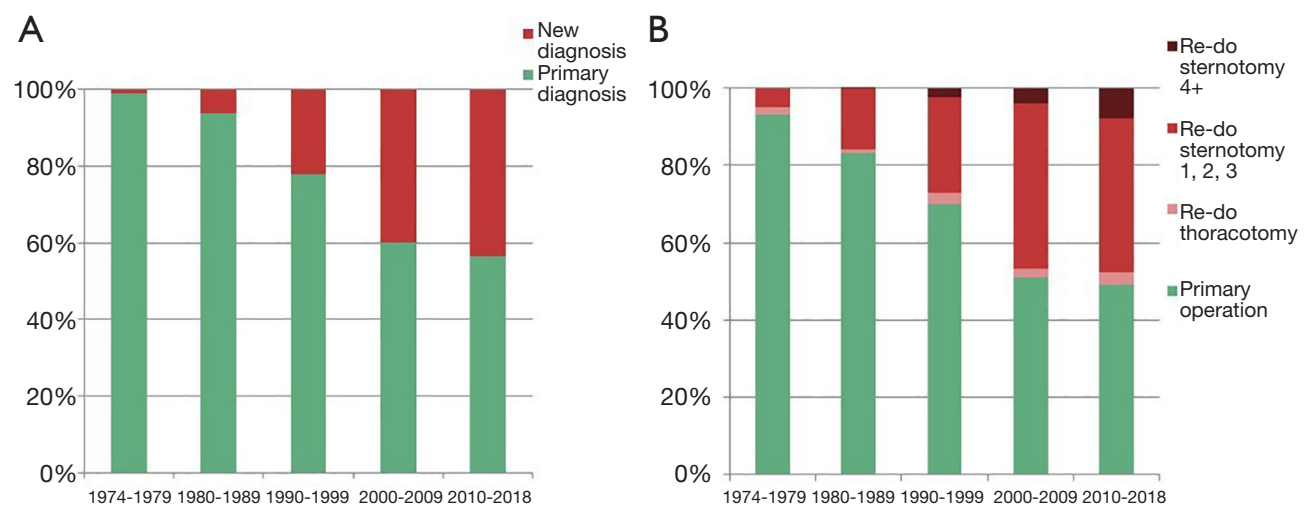

Figure 3 Adults with congenital heart disease undergoing cardiac surgery between 1974 and 2018 in German Heart Centre Munich. (A) Cumulative percentage of primary diagnosis versus new diagnosis leading to the index cardiac operation, shown for each decade; (B) cumulative percentage of the first operation versus reoperations, shown for each decade. 
A

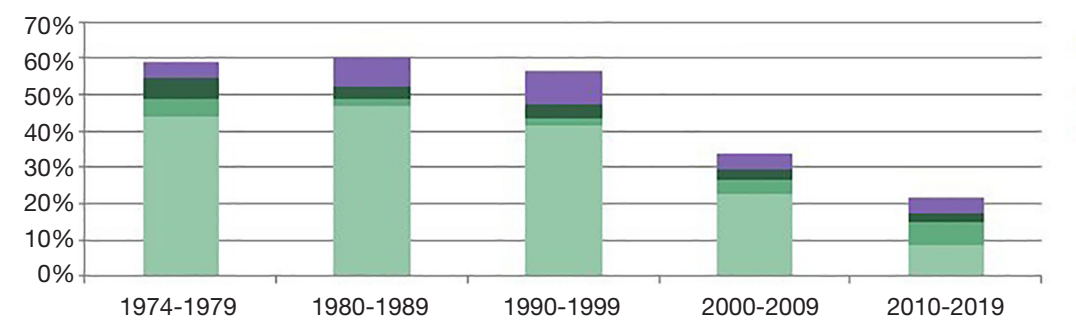

- VSD

- Common AV canal repair (incomplete) - PAPVC repair

$\because \mathrm{ASD}$

B

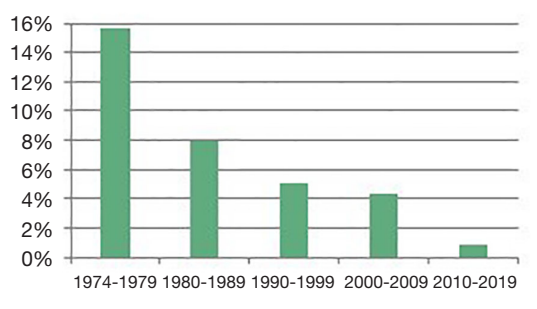

D Aortic valve

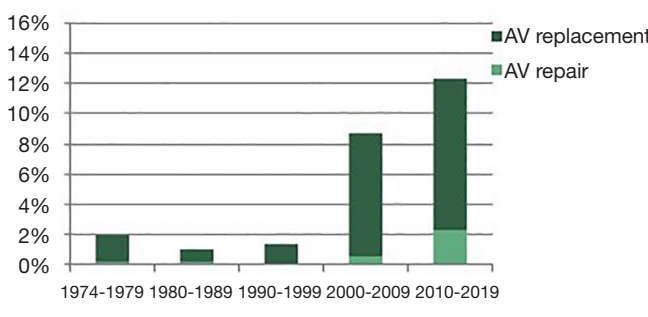

F Pulmonary valve

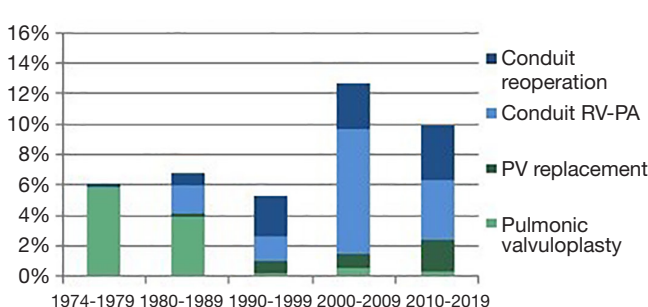

1974-1979 1980-1989 1990-1999 2000-2009 2010-2019
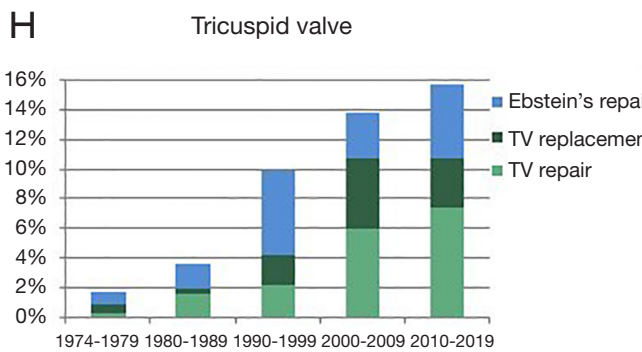

C Aortic root and aorta ascendens

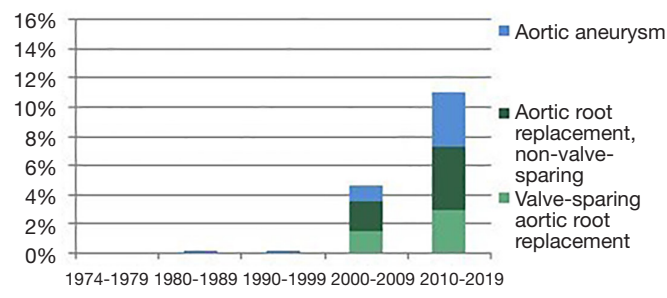

E Mitral valve

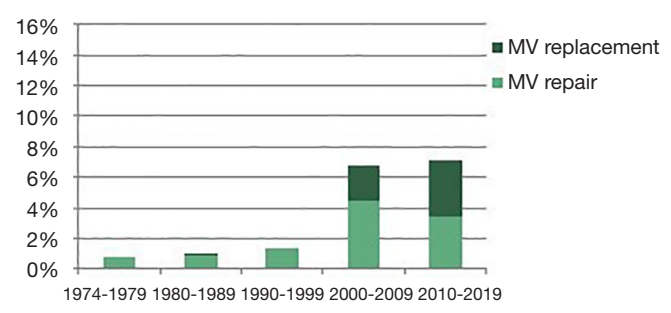

G Right heart lesions

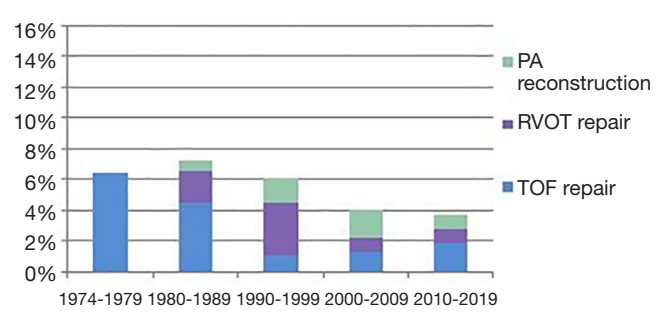

I Fontan

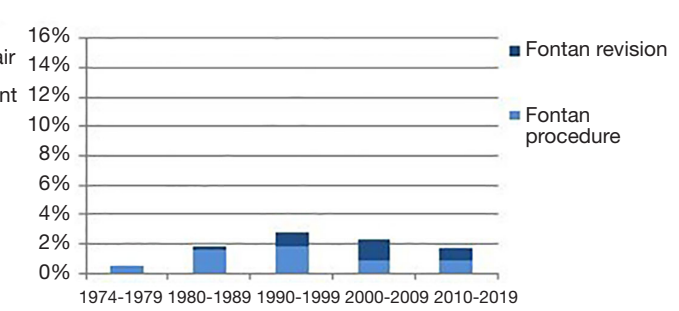

Figure 4 Primary procedures on adults with congenital heart disease undergoing cardiac surgery between 1974 and 2018 in German Heart Centre Munich shown as the relative frequency of all operations in each decade. (A) Septal defects; (B) coarctation repair; (C) operations on the aortic root and the ascending aorta; (D) operations on the AV; (E) operations on the mitral valve; (F) operations on the pulmonary valve; (G) operations for right heart lesions, excluding the pulmonary valve itself; (H) operations on the tricuspid valve; (I) Fontan procedures and revisions. ASD, atrial septal defect; AV, aortic valve; AV canal, atrioventricular canal; MV, mitral valve; PA, pulmonary artery; PAPVC, partial anomalous pulmonary venous connection; PV, pulmonary valve; RV, right ventricle; RVOT, right ventricular outflow tract; TOF, tetralogy of Fallot; TV, tricuspid valve; VSD, ventricular septal defect. 
significantly from the '70s to ' 90 s $(\mathrm{P}=0.016)$ and then raised again continually in the ' 00 s and ' 10 s ( $\mathrm{P}$ ranged from $<0.001$ to 0.045$)$. Relatively more corrections of the incomplete atrioventricular canal were done in the 70 s when compared to ' $00 \mathrm{~s}(\mathrm{P}=0.044)$ and ' $10 \mathrm{~s}(0.012)$. Relative frequency of VSD closures first raised significantly from the ' 70 s to ' $80 \mathrm{~s}$ $(\mathrm{P}=0.023)$, and then returned to the previous levels in ' $00 \mathrm{~s}$ and '10s (P ranged from $<0.001$ to 0.004 ).

Coarctation repair (Figure $4 B$ ) was most frequently performed in the '70s, then dropped significantly in the " $80 \mathrm{~s}$ ( $\mathrm{P}>0.001)$. This was followed by a stagnation in the relative frequency in the ' $90 \mathrm{~s}$ and ' $00 \mathrm{~s}$, and the next significant drop in the '10s $(\mathrm{P}<0.001)$.

Operations of the aortic root and the ascending aorta (Figure 4C): valve-sparing root replacement, first introduced in the '00s, stayed stable in relative frequency in the ' $10 \mathrm{~s}$ $(\mathrm{P}=0.077)$. Non-valve-sparing aortic root replacement, also first introduced in the ' 00 s, increased in relative frequency in the ' $10 \mathrm{~s}(\mathrm{P}=0.002)$. The ratio of the valve-sparing to nonvalve-sparing aortic root replacements stayed the same in the '00s and '10s $(\mathrm{P}=0.813)$. Aortic aneurysm repair was rarely performed before the '00s, but then significantly increased in the " $10 \mathrm{~s}(\mathrm{P}=0.002)$.

Operations on the AV (Figure 4D): AV repair was performed very rarely before the ' 10 s when it increased significantly in comparison to the ' $00 \mathrm{~s}(\mathrm{P}=0.005)$. $\mathrm{AV}$ replacement was rarely performed before the ' 00 s when it increased and then stayed stable in relative frequency in the '10s $(\mathrm{P}=0.237)$. The ratio of $\mathrm{AV}$ repair to $\mathrm{AV}$ replacement also increased significantly from the '00s and ' $10 \mathrm{~s}(\mathrm{P}=0.028)$.

Operations on the mitral valve (MV) (Figure 4E): MV repair was performed with similar low relative frequency from the '70s to ' 90 s, then increased significantly in ' $00 \mathrm{~s}$ $(\mathrm{P}=0.003)$ and stayed on the same level in the ' $10 \mathrm{~s}(\mathrm{P}=0.351)$. MV replacement was rarely performed before the ' 00 s when it increased and then stayed stable in relative frequency in the ' $10 \mathrm{~s}(\mathrm{P}=0.128)$. The ratio of $\mathrm{MV}$ repair to $\mathrm{MV}$ replacement stayed similar in the ' $00 \mathrm{~s}$ and ' $10 \mathrm{~s}(\mathrm{P}=0.109)$.

Operations on the pulmonary valve (PV) (Figure $4 F)$ : pulmonic valvuloplasty was performed with similar relative frequency in the " 70 s and ' $80 \mathrm{~s}(\mathrm{P}=0.200)$ and then decreased to '90s $(\mathrm{P}<0.001)$. Since then, it stayed on the same low level (P ranged from 0.654 to 1.000). PV replacement was performed rarely, with the highest relative frequency in the " $10 \mathrm{~s}$. When compared to the " $70 \mathrm{~s}$ and ' 80 s, the frequency in the " 10 s was statistically higher $(\mathrm{P}=0.004$ and 0.001 respectively). Conduit implantation from the right ventricle to the pulmonary artery (RV-PA) increased in the '80s $(\mathrm{P}=0.009)$, stayed on a similar level in the '90s $(\mathrm{P}=0.818)$, then increased significantly in the '00s $(\mathrm{P}<0.001)$, decreasing again in the '10s $(\mathrm{P}=0.001)$. The relative frequency in the " 10 s stayed clearly over the frequency in the $90 \mathrm{~s}(\mathrm{P}=0.024)$. Conduit reoperations increased in the ' $90 \mathrm{~s}(\mathrm{P}=0.015)$ and then stayed on a stable level (P ranged from 0.405 to 0.733 ).

Operations for right heart lesions, excluding the $\mathrm{PV}$ itself (Figure 4G): tetralogy of Fallot (TOF) repair was performed primarily in the " 70 s and '80s with similar relative frequency $(\mathrm{P}=0.223)$. Then it decreased significantly in the '90s $(\mathrm{P}=0.001)$ and stayed on a similarly low level ( $\mathrm{P}$ ranging from 0.336 to 0.793 ). Right ventricular outflow tract (RVOT) repair was performed in the ' 80 s and ' 90 s with similar relative frequency $(\mathrm{P}=0.257)$ and then reduced significantly in '00s $(\mathrm{P}=0.002)$, staying on that reduced level in the '10s $(\mathrm{P}=1.000)$. Pulmonary artery $(\mathrm{PA})$ reconstruction started in the ' 80 s and was since then performed with similar relative frequency ( $\mathrm{P}$ ranged from 0.244 to 0.830 ).

Operations on the tricuspid valve (TV) (Figure 4H): TV repair was performed with similar low relative frequency from the '70s to ' $90 \mathrm{~s}$, then increased significantly in ' $00 \mathrm{~s}$ $(\mathrm{P}=0.001)$ and stayed on the same level in the ' $10 \mathrm{~s}(\mathrm{P}=0.295)$. TV replacement increased from the ' 80 s to ' $90 \mathrm{~s}(\mathrm{P}=0.016)$, and then to '00s $(\mathrm{P}=0.013)$, staying on this level in the '10s $(\mathrm{P}=0.186)$. There was no significant difference in the ratio of TV repair to TV replacement since the '90s (P ranged from 0.101 to 0.809$)$. Ebstein's repair increased significantly in the relative frequency in the $90 \mathrm{~s}(\mathrm{P}<0.001)$. It then dropped in the '00s $(\mathrm{P}=0.030)$, reaching again similar frequencies in the ' $10 \mathrm{~s}(\mathrm{P}=0.694)$. The increase between the ' $00 \mathrm{~s}$ and ' $10 \mathrm{~s}$, however, was not statistically significant $(\mathrm{P}=0.084)$.

Fontan procedures and revisions (Figure $4 I$ ): the Fontan procedure was performed with similar low relative frequency throughout the entire observed period ( $\mathrm{P}$ ranged from 0.132 to 1.000$)$. Fontan revision was rarely performed before the ' 90 s when it increased and then stayed stable in relative frequency (P ranging from 0.339 to 0.770 ).

Atrial surgical ablation started in the '80s with very low relative frequency $(0.7 \%)$, and first rose significantly in the ' 10 s to the relative frequency of $3.2 \%$ ( $\mathrm{P}=0.005$ compared to '00s). Systemic-to pulmonary shunt implantation was performed with similar low relative frequency from the "70s to the '00s. Compared with the '70s, and ' 80 s, the frequency in the ' 10 s dropped significantly $(\mathrm{P}=0.019$ and 0.03 respectively) to practically zero (1 of 697 operations). Coronary artery bypass was done only in the last decade, with a relative frequency of $2.4 \%$ (17 of 697 operations). 


\section{Discussion}

In 1974, the German Heart Centre Munich opened its doors as the first "single-organ" clinic in Europe. On April $19^{\text {th }} 1974$, the first operation in the German Heart Centre was performed, the patient being an adult with a congenital heart defect. A 57-year-old woman with a secundum ASD underwent a direct closure of the defect. She stayed on the intensive care unit for 6 days, without any complications. During the following 45 years, 2,882 operations were performed on ACHD. The spectrum of cardiac surgery in ACHD changed significantly over this period, from primary corrections of septal defects and coarctation of the aorta in the 1970s to complex reoperations in the 2010s.

The population of ACHD is steadily increasing (5) and getting older $(1,4)$. Even with continuously improving medical and interventional therapeutical options, some of these patients will require cardiac surgery during their lifetime. The number of cardiac operations in ACHD is reported to reach 1.2-2.3 operations per 100 patient-years, depending on the age group of ACHD $(14,15)$. In our study, the number of procedures performed in ACHD per year increased slowly, but steadily. The median age of ACHD at the time of the cardiac operation increased only slightly during the period of 45 years, to 34.1 years of age in the 2010s. Overall operative mortality was $3.2 \%$. There was no significant difference in mortality over the decades.

In the 1970s the ACHD were operated exclusively for correction of CHD. The closure of septal defects constituted $59 \%$ of all operations. Three-quarters of these operations were for the secundum ASD, the rest for sinus venosus defect with PAPVC, incomplete atrioventricular septal defect, and VSD. Coarctation repair was done in $16 \%$ of the cases. Repair of TOF and pulmonary valvuloplasty made up the next $12 \%$ of the operations. Four percent of the operations were surgical closures of a patent ductus arteriosus (PDA). From all of the operations in the 1970s, $7 \%$ were reoperations. Most of these were the repair of TOF after a prior shunt implantation $(25 \%)$ or residual ASD closures (17\%).

In the 1980s, the surgery in ACHD was also mostly performed for the correction of CHD. The closures of septal defect stayed at a similar level with $61 \%$. The secundum ASD was still the most common of the septal defects causing $47 \%$ of all operations, followed by VSD whose closure raised significantly in the 1980 s, to $8 \%$ of all operations. Coarctation repair, on the other hand, reduced significantly to $8 \%$. Repair of TOF and pulmonary valvuloplasty stayed on the same levels and constituted $8 \%$ of the operations as well. The first RV-PA conduits in ACHD were implanted in this decade and reached a relative frequency of $2 \%$. PDA closure was still performed with a relative frequency of $4 \%$. The proportion of reoperations went up to $17 \%$ of all operations. Operations on the right heart, including TOF repair after prior shunt implantation, RV-PA conduit placement, conduit reoperation, RVOT procedure and $\mathrm{PA}$ reconstruction made up $35 \%$ of the reoperations in the 1980s.

In the 1990s, the closure of septal defects continued to constitute the majority of ACHD operations with $56 \%$, the isolated closure of the secundum ASD $41 \%$. Coarctation repair stayed on a similar level with a relative frequency of $5 \%$. However, TOF repair and pulmonary valvuloplasty decreased significantly to a level of $1 \%$. This was undoubtedly a result of a considerable improvement in the congenital heart surgery during the 1980s when the neonatal heart surgery was introduced in the clinical practice (16). The experience of the congenital heart surgeons increased, and almost all patients with CHD could receive a total repair or definitive palliation during the childhood years. Another progress made in the 1980s had a significant effect on the spectrum of cardiac surgery in ACHD. In the era of routine transcatheter closure of PDA $(17,18)$, the isolated surgical closure of PDA decreased significantly in the 1990s and was not performed afterwards. In the 1990s, there was a noticeable increase in TV surgery, which constituted $10 \%$ of all operations. Mainly, the relative frequency of the repair of the Ebstein's anomaly increased and made up $6 \%$ of all operations. This was influenced by the institutional development (19) and increasing experience $(20,21)$ with creating a monocusp valve with the single-stitch technique in Ebstein patients. The proportion of reoperations increased again significantly compared to the previous decade, to $30 \%$ of all operations. RV-PA conduit placements and conduit reoperations made up $20 \%$ of the reoperations in the 1990s. Of note are the following $13 \%$ of the reoperations, which included complex revisions or creations of the atrial baffle in patients with transposition of the great arteries, and Fontan procedures or revisions. Seven percent of the ACHD patients undergoing a reoperation had at least four cardiac operations previously.

In the 2000s, several significant changes in the spectrum of the surgery in ACHD took place. The closures of septal defects, which were the central part of the surgery in the previous 25 years, decreased significantly to $34 \%$ of all operations. Although the first interventional closure of the 
ASD was performed in 1975 (22), the 1990s brought several different occluder devices to the market, some of which, like Amplatzer Septal Occluder (23) have since been used extensively worldwide. The result of this was seen in the 2000s as the surgical closure of secundum ASDs almost halved and dropped to $23 \%$ of all operations in ACHD at the German Heart Centre. The relative frequency on VSD closure also dropped significantly. Although transcatheter closure of VSD was slowly increasing after the first success in the 1980s (24), it is more likely that the improvements in diagnostics and surgical management of the paediatric patients with CHD in the previous decades have led to the decrease in the adults with VSD in need of cardiac surgery. The coarctation repair stayed on a stable level of $4 \%$ in the 2000s. On the other side, valve surgery increased immensely in the numbers. AV replacement, which was previously done only sporadically, constituted $8 \%$ of all operations. Next to this, the first aortic root and ascending aorta operations were performed in ACHD in the 2000s, immediately reaching a relative frequency of $5 \%$. MV surgery, both repair and replacement, were also performed only occasionally before the 2000s. They increased in this decade to make up $7 \%$ of all operations. Ebstein's repair stayed on the same level as in the 1990s. However, TV repair and replacement increased significantly so that TV surgery altogether constituted $14 \%$ of all operations in ACHD in the 2000s. Operations involving PV also increased significantly to make up $13 \%$ of all operations, mostly due to a significant increase in the number of implanted RV$\mathrm{PA}$ conduits and conduit reoperations. One of the possible reasons for an increase in the RV-PA conduits (and not PV) implantations lies in the establishment of the institutional homograft bank in the 2000s. Altogether, it can be said that the surgery in ACHD changed in the 2000s from septal defect surgery into valve surgery, the spectrum of which affected all four valves. The cumulative frequency of valve operations in the 2000 s reached $46 \%$ of all operations. The proportion of reoperations increased significantly compared to the previous decade, to $49 \%$ of all operations. RV-PA conduit placements and conduit reoperations made up 26\% of the reoperations in the 2000s. Repair and replacements of aortic, mitral and TV constituted the next $34 \%$ of the reoperations. Eight per cent of the reoperations were $4^{\text {th }}+$ reoperations.

In the 2010s, the closures of septal defects decreased further to only $22 \%$ of all operations. Again, the relative frequency of the secundum ASD closures decreased significantly to $9 \%$. In this decade the coarctation repair also decreased significantly to only $1 \%$ of all operations. This was the result of significant advances in interventional treatment of the aortic coarctation using balloon dilatation and stenting (25). Surgery of aortic root and the ascending aorta increased significantly in the 2010 s to $11 \%$. AV repair also increased in relative frequency, while AV replacement, MV surgery and TV surgery stayed on the same high level as in the 2000s. Due to the introduction of the Cone technique in the German Heart Centre (26), the number of Ebstein's repairs raised. RV-PA conduit implantations reduced significantly from $8 \%$ in the 2000 s to $4 \%$ in 2010s. The reason for this might be found in the improved possibilities of transcatheter PV implantation $(27,28)$. Interestingly, the number of conduit reoperations stayed the same. The cumulative frequency of valve operations in the 2010 s was $53 \%$ of all operations. In other highly specialised centres, also more than $50 \%$ of all operations on ACHD are performed to restore valvular patency and competence (9). Atrial surgical ablation, rarely performed before the 2000s, increased significantly in the last decade to the relative frequency of $3 \%$. Systemic-to pulmonary shunt implantation, which was performed with similar low relative frequency up to the 2000 s, almost disappeared from the operation spectrum in the 2010s. On the other hand, coronary artery bypass, which was not performed in the previous decades in ACHD patients, reached a relative frequency of $2 \%$ in the 2010 s. The reported mean age of ACHD who present for cardiac surgery with significant acquired coronary artery disease is 66 years (29). In our collective, only $2 \%$ of the patients were 66 years of age and older. Reports show, however, that there is an 8-fold increase in ACHD presenting at the outpatient clinic at an age over 60 years since the year 2000 (14). The problem of acquired heart disease in ACHD is still to come. The proportion of the reoperations stayed on the level of 2000s, constituting $51 \%$ of all operations, which is consistent with current reports of other specialised centres (30). However, the proportion of the $4^{\text {th }}+$ reoperations raised significantly to $15 \%$ of all reoperations. Recent studies showed that a high number of previous sternotomies in an ACHD patient might be a risk factor for increased early mortality (31).

\section{Limitations}

This is a single-centre retrospective study over a long period of almost five decades. The results might be significantly influenced by the institutional policies during the investigated period. The results cannot be generalized 
to other centres or countries since the effect of potential changes in referrals from national and international hospitals as well as the changes in operative capacity within the German Heart Centre are not covered by the study.

\section{Conclusions}

The spectrum of surgery in ACHD changed significantly over the decades. There was a significant decrease in the relative frequency of ASD closures from $45 \%$ in the 1970 s and 1980 s to $9 \%$ in 2010s. Coarctation repair made up $15 \%$ of all operations in the 1970s, then reduced significantly to $1 \%$ in the 2010 s. The percentage of reoperations increased significantly from $7 \%$ in the 1970 s to $51 \%$ in 2010s. The surgical therapy changed from primary repair of septal defects and coarctation to complex reoperations as treatment of residual defects or sequelae of the initial pathology or previous treatment. It is to be expected that the acquired heart disease will start mixing with the congenital heart defects in the upcoming years.

\section{Acknowledgments}

Funding: None.

\section{Footnote}

Provenance and Peer Review: This article was commissioned by the editorial office, Cardiovascular Diagnosis and Therapy for the series "Current Management Aspects in Adult Congenital Heart Disease (ACHD): Part III". The article has undergone external peer review.

Reporting Checklist: The authors have completed the SURGE reporting checklist. Available at http://dx.doi. org/10.21037/cdt-20-831

Data Sharing Statement: Available at http://dx.doi. org/10.21037/cdt-20-831

Conflicts of Interest: All authors have completed the ICMJE uniform disclosure form (available at http:// dx.doi.org/10.21037/cdt-20-831). The series "Current Management Aspects in Adult Congenital Heart Disease (ACHD): Part III" was commissioned by the editorial office without any funding or sponsorship. HK serves as an unpaid editorial board member of Cardiovascular Diagnosis and Therapy from Feb 2018 to Jan 2022 and served as the unpaid Guest Editor of the series. RL reports other from Medtronic, other from Abbott, other from Highlife, outside the submitted work. The authors have no other conflicts of interest to declare.

Ethical Statement: The authors are accountable for all aspects of the work in ensuring that questions related to the accuracy or integrity of any part of the work are appropriately investigated and resolved. Institutional Review Board approval was obtained to conduct this study (Ethikkommission an der Technischen Universität München 40/20 S). The study was conducted in accordance with the Declaration of Helsinki (as revised in 2013).

Open Access Statement: This is an Open Access article distributed in accordance with the Creative Commons Attribution-NonCommercial-NoDerivs 4.0 International License (CC BY-NC-ND 4.0), which permits the noncommercial replication and distribution of the article with the strict proviso that no changes or edits are made and the original work is properly cited (including links to both the formal publication through the relevant DOI and the license). See: https://creativecommons.org/licenses/by-nc-nd/4.0/.

\section{References}

1. Khairy P, Ionescu-Ittu R, Mackie AS, et al. Changing mortality in congenital heart disease. J Am Coll Cardiol 2010;56:1149-57.

2. Marelli AJ, Mackie AS, Ionescu-Ittu R, et al. Congenital Heart Disease in the General Population. Circulation 2007;115:163-72.

3. Moons P, Bovijn L, Budts W, et al. Temporal trends in survival to adulthood among patients born with congenital heart disease from 1970 to 1992 in Belgium. Circulation 2010;122:2264-72.

4. Warnes CA. The adult with congenital heart disease: born to be bad? J Am Coll Cardiol 2005;46:1-8.

5. Marelli AJ, Ionescu-Ittu R, Mackie AS, et al. Lifetime Prevalence of Congenital Heart Disease in the General Population From 2000 to 2010. Circulation 2014;130:749-56.

6. Vida VL, Berggren H, Brawn WJ, et al. Risk of surgery for congenital heart disease in the adult: a multicentered European study. Ann Thorac Surg 2007;83:161-8.

7. Hörer J. Current spectrum, challenges and new developments in the surgical care of adults with congenital heart disease. Cardiovasc Diagn Ther 2018;8:754-64. 
8. Neidenbach R, Niwa K, Oto O, et al. Improving medical care and prevention in adults with congenital heart diseasereflections on a global problem-part I: development of congenital cardiology, epidemiology, clinical aspects, heart failure, cardiac arrhythmia. Cardiovasc Diagn Ther 2018;8:705-15.

9. Hörer J, Belli E, Roussin R, et al. Evaluation of the Adult Congenital Heart Surgery Mortality Score at Two European Centers. Ann Thorac Surg 2018;105:1441-6.

10. Beurtheret $S$, Tutarel O, Diller GP, et al. Contemporary cardiac surgery for adults with congenital heart disease. Heart 2017;103:1194-202.

11. World Medical Association. World Medical Association Declaration of Helsinki: ethical principles for medical research involving human subjects. JAMA 2013;310:2191-4.

12. Fuller SM, He X, Jacobs JP, et al. Estimating Mortality Risk for Adult Congenital Heart Surgery: An Analysis of The Society of Thoracic Surgeons Congenital Heart Surgery Database. Ann Thorac Surg 2015;100:1728-35; discussion 1735-6.

13. Jacobs JP, Mavroudis C, Jacobs ML, et al. What is operative mortality? Defining death in a surgical registry database: a report of the STS Congenital Database Taskforce and the Joint EACTS-STS Congenital Database Committee. Ann Thorac Surg 2006;81:1937-41.

14. Tutarel O, Kempny A, Alonso-Gonzalez R, et al. Congenital heart disease beyond the age of 60 : emergence of a new population with high resource utilization, high morbidity, and high mortality. Eur Heart J 2014;35:725-32.

15. Ionescu-Ittu R, Mackie AS, Abrahamowicz M, et al. Valvular operations in patients with congenital heart disease: increasing rates from 1988 to 2005. Ann Thorac Surg 2010;90:1563-9.

16. Bove EL BC, Stark J, de Leval M, Macartney FJ, Taylor JFN. Congenital heart disease in the neonate: results of surgical treat- ment. Arch Dis Child 1983;58:137-41.

17. Hosking MC, Benson LN, Musewe N, et al. Transcatheter occlusion of the persistently patent ductus arteriosus. Forty-month follow-up and prevalence of residual shunting. Circulation 1991;84:2313-7.

18. Rashkind WJ, Mullins CE, Hellenbrand WE, et al. Nonsurgical closure of patent ductus arteriosus: clinical application of the Rashkind PDA Occluder System. Circulation 1987;75:583-92.

19. Schmidt-Habelmann P, Meisner H, Struck E, et al. Results of valvuloplasty for Ebstein's anomaly. Thorac Cardiovasc Surg 1981;29:155-7.

20. Augustin N, Schmidt-Habelmann P, Wottke M, et al.
Results after surgical repair of Ebstein's anomaly. Ann Thorac Surg 1997;63:1650-6.

21. Augustin N, Schreiber C, Wottke M, et al. Ebstein's anomaly: when should a patient have operative treatment? Herz 1998;23:287-92.

22. King TD, Thompson SL, Steiner C, et al. Secundum Atrial Septal Defect: Nonoperative Closure During Cardiac Catheterization. JAMA 1976;235:2506-9.

23. Masura J, Gavora P, Formanek A, et al. Transcatheter closure of secundum atrial septal defects using the new self-centering amplatzer septal occluder: initial human experience. Cathet Cardiovasc Diagn 1997;42:388-93.

24. Lock JE, Block PC, McKay RG, et al. Transcatheter closure of ventricular septal defects. Circulation 1988;78:361-8.

25. Salcher M, Naci H, Law TJ, et al. Balloon Dilatation and Stenting for Aortic Coarctation: A Systematic Review and Meta-Analysis. Circ Cardiovasc Interv 2016;9:e003153.

26. Lange R, Burri M, Eschenbach LK, et al. Da Silva's cone repair for Ebstein's anomaly: effect on right ventricular size and function. Eur J Cardiothorac Surg 2015;48:31620; discussion 320-1.

27. Kheiwa A, Divanji P, Mahadevan VS. Transcatheter pulmonary valve implantation: will it replace surgical pulmonary valve replacement? Expert Rev Cardiovasc Ther 2018;16:197-207.

28. Eicken A, Ewert P, Hager A, et al. Percutaneous pulmonary valve implantation: two-centre experience with more than 100 patients. Eur Heart J 2011;32:1260-5.

29. Giamberti A, Lo Rito M, Conforti E, et al. Acquired coronary artery disease in adult patients with congenital heart disease: a true or a false problem? J Cardiovasc Med (Hagerstown) 2017;18:605-9.

30. Hörer J, Roussin R, LeBret E, et al. Validation of the grown-ups with congenital heart disease score. Heart 2018;104:1019-25.

31. Holst KA, Dearani JA, Burkhart HM, et al. Risk factors and early outcomes of multiple reoperations in adults with congenital heart disease. Ann Thorac Surg 2011;92:122-8; discussion 129-30.

Cite this article as: Pabst von Ohain J, Tonino E, Kaemmerer H, Cleuziou J, Ewert P, Lange R, Hörer J. German Heart Centre Munich -45 years of surgery in adults with congenital heart defects: from primary corrections of septal defects and coarctation to complex reoperations. Cardiovasc Diagn Ther 2021;11(2):492-502. doi: 10.21037/cdt-20-831 